\title{
Behavior of RBS Beams Reinforced by Stiffeners Subjected to Cyclic Loading
}

\author{
Iori Kanao ${ }^{(D)}{ }^{1}$ Tianrui He, ${ }^{1}$ Zheng Yu, ${ }^{2}$ and Kiyotaka Morisako ${ }^{1}$ \\ ${ }^{1}$ Kyoto Institute of Technology, Matsugasaki, Sakyo-ku, Kyoto 6068585, Japan \\ ${ }^{2}$ MCC Capital Engineering \& Research Incorporation Limited, Daxing District, Beijing 100176, China \\ Correspondence should be addressed to Iori Kanao; kanao@kit.ac.jp
}

Received 29 November 2017; Accepted 29 January 2018; Published 1 March 2018

Academic Editor: Mario D’Aniello

Copyright (c) 2018 Iori Kanao et al. This is an open access article distributed under the Creative Commons Attribution License, which permits unrestricted use, distribution, and reproduction in any medium, provided the original work is properly cited.

\begin{abstract}
This paper presents a numerical study of reduced beam section (RBS) beams with vertical and horizontal stiffeners. For RBS beams, it is speculated that strength deterioration will be caused by lateral buckling and local buckling. Supplemental lateral bracing (SLB) can prevent lateral buckling but not prevent local buckling in the RBS portion. In the previous research, the effect of vertical or horizontal stiffeners in RBS portion was shown to restrain local buckling of the RBS portion. But RBS with vertical stiffeners causes stress concentration at flange, and strength of RBS with horizontal stiffeners is lower than RBS with vertical stiffeners. In this paper, various patterns of placing stiffeners at the RBS portion are presented. The effect of vertical stiffeners and horizontal stiffeners arranged at the RBS portion is discussed based on length. It is confirmed that, without placing supplemental lateral bracing (SLB), vertical and horizontal stiffeners can delay the occurrence of local buckling and prevent stress concentration. Moreover, the strength can be sustained above $0.8 M_{p}$.
\end{abstract}

\section{Introduction}

In Northridge earthquake and Kobe earthquake, serious damage occurred. Damage of beam-to-column joints of steel structures was especially critical. From the damage investigation, Reduced Beam Section (RBS) has been proposed for improving the plastic rotation capacity of the beam-tocolumn joints. The high plastic rotation capacity of RBS has been shown experimentally, and the design code has been proposed (Engelhardt and Sabol [1], Uang and Fan [2]). However, it is speculated that lateral buckling or local buckling might be easier to occur, because of deterioration of stiffness of the RBS portion. In design code, arrangement of supplemental lateral bracings is provided for lateral buckling, but there is no provision for local buckling. For preventing strength degradation due to local buckling, Li et al. [3] proposed placing vertical stiffeners within the RBS portion. However, placing vertical stiffener tends to increase stress in RBS portion of the flange. Alternatively, Yu et al. [4] proposed placing horizontal stiffeners. The RBS beam with horizontal stiffeners certainly prevents stress concentration, but its strength is lower than RBS beam with vertical stiffeners.
This paper presents the effect of the vertical and horizontal stiffener at the RBS portion on the basis of [3-5] and proposes the method for sustaining the deformation capacity of RBS beam.

\section{Deformation Capacity of RBS Beams with Stiffeners Subjected to Cyclic Loading}

2.1. Analysis Model. In this study, a general finite-element method (FEM) program MSC. MARC 2013 was used. As shown in Figure 1(a), the analysis model is a half-span length $(L / 2)$ cantilever beam with a concentration load at the freeend.

The beam cross sections are $W 24 \times 76, W 30 \times 99$, and $W 36 \times 194$. The slenderness ratio of the three beams is 73.2 , because the slenderness ratio $\left(L / r_{y}\right)$ of RBS beam should be less than 77 (according to ANSI/AISC 341-10 [6]). The cross section properties are shown in Table 1 . At the fixed-end section, all displacements and rotations of all nodes are restrained. At the free-end section, only $Y$-displacement of the central node is restrained. The elements of flange and 


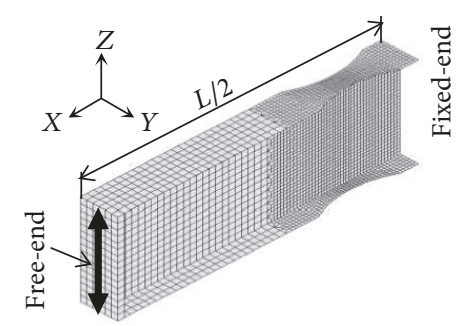

(a)
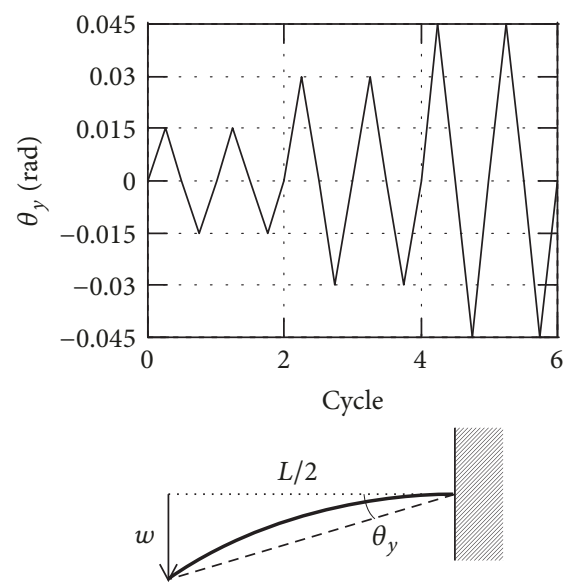

(b)
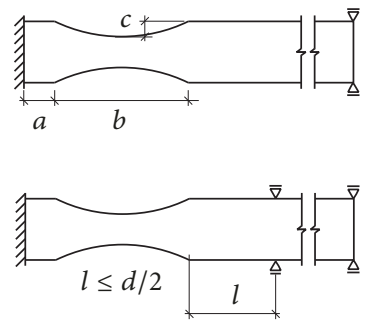

(c)
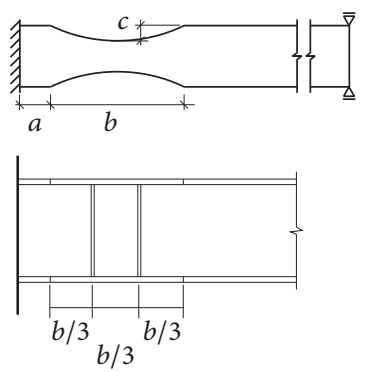

(d)
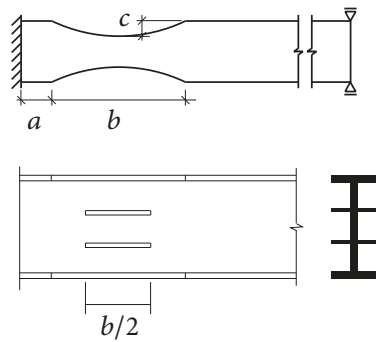

(e)

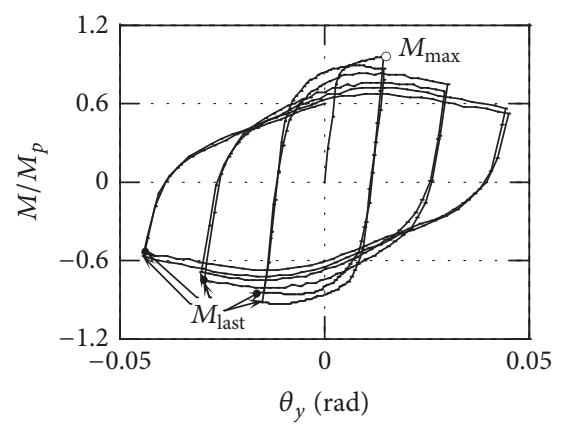

(f)

FIGURE 1: Beam modeling: (a) cantilever representation and discretization ([4]); (b) loading history ([4]) and definition of beam-end rotation; (c) details of the RBS portion and the RBS beam with supplemental lateral bracings ([4]); (d) detail of the RBS beam with vertical stiffeners $([3,4]) ;(e)$ detail of the RBS beam with horizontal stiffeners; and (f) definition of strength measures ([4]).

TABle 1: Properties of beam.

\begin{tabular}{lccccccc}
\hline & $I_{x}\left(\mathrm{~mm}^{4}\right)$ & $r_{y}(\mathrm{~mm})$ & $L(\mathrm{~mm})$ & Width-thickness ratio & $a(\mathrm{~mm})$ & $b(\mathrm{~mm})$ & $c(\mathrm{~mm})$ \\
\hline$W 24 \times 76$ & $8.50 \times 10^{8}$ & 48.91 & 3580 & 52.2 & 114 & 494 \\
$W 30 \times 99$ & $1.62 \times 10^{9}$ & 53.66 & 3928 & 55.3 & 132 & 621 \\
$W 36 \times 194$ & $4.96 \times 10^{9}$ & 65.8 & 4816 & 45.4 & 154 & 66 \\
\hline
\end{tabular}

web are four-node thick-shell elements, and a plate is set at the free-end modeled by eight-node solid elements. The portion near the fixed-end and a range about 1.2 times the beam height that sustains plastic deformation is divided into $25 \mathrm{~mm} \times 25 \mathrm{~mm}$ elements, and the other portion is divided into about $50 \mathrm{~mm} \times 50 \mathrm{~mm}$. Young's modules of the material is $2.1 \times 10^{5} \mathrm{MPa}$. The stress-strain relation adopted a bilinear model, in which the second stiffness is $E / 100$ and the yield stress is $235 \mathrm{MPa}$. As shown in Figure 1(b), the beam is loaded cyclically with increasing beam-end rotation amplitude $\left(\theta_{y}=\right.$ $w /(L / 2))$ of $0.015,0.030$, and $0.045 \mathrm{rad}$, performing each loadamplitude in two cycles. According to the ANSI/AISC358-10 [7], supplemental lateral bracing (SLB) has to be located in the range of $0.5 h$ from the end of the RBS that is farthest from the column face (Figure 1(c)). Figure 1(d) shows RBS beam with vertical stiffeners ( $\mathrm{Li}$ et al. [3]), and Figure 1(e) shows RBS beam with horizontal stiffeners (Yu et al. [4]). In Li et al. [3], the accuracy of the FEM predictions of significant local buckling was assessed by comparing the FEM results to a physical test of a full-scale beam-column subassemblage by Engelhardt [8]. The analysis condition in this paper is according to Li et al. [3].

In the following observations, the maximum strength during the whole loading history $\left(M_{\max }\right)$ and the strength at the each cycle named "last strength" $\left(M_{\text {last }}\right)$ in this paper are adopted as the strength index (Figure 1(f)). When the moment of cross section of RBS portion is full plastic moment, the beam-end moment is $0.8 M_{p} . M_{p}$ is the full plastic moment for full section.

\subsection{Behavior of RBS Beam without Stiffener, Vertical Stiffener,} and Horizontal Stiffeners. Figure 2 shows the relationship between the beam-end moment $(M)$ and the beam-end rotation for $W 36 \times 194$ beams. The beam-end rotation is calculated by the vertical displacement of loading point divided by beam length $(L / 2)$. Figure $2(\mathrm{a})$ is the graph of beam without SLB and stiffeners (called "Standard RBS"), (b) is the beam braced by SLB (called "RBS-SLB"), (c) is the beam with 


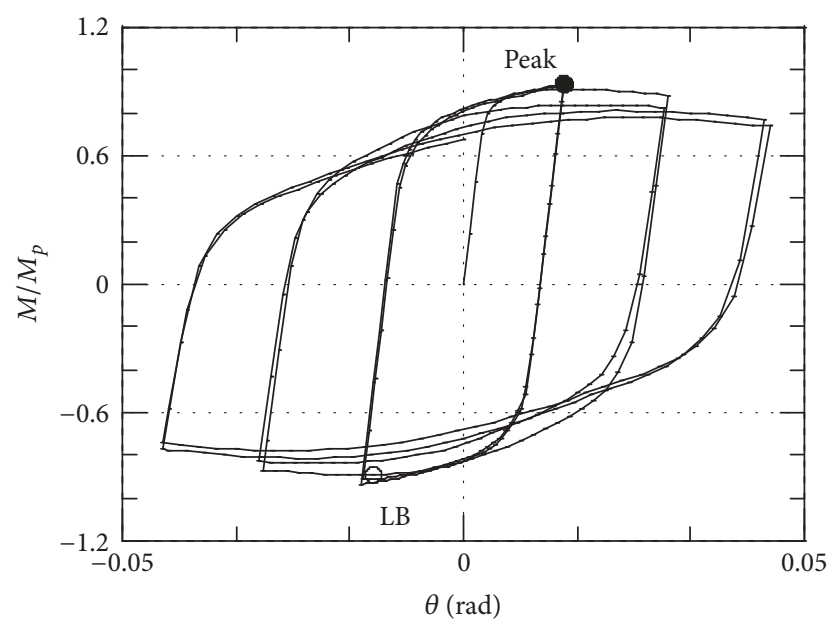

(a)

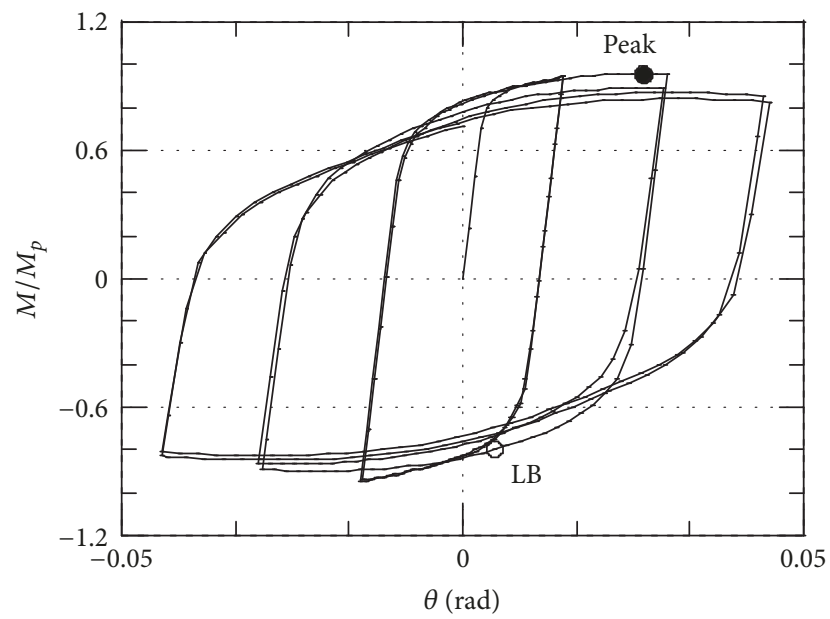

(c)

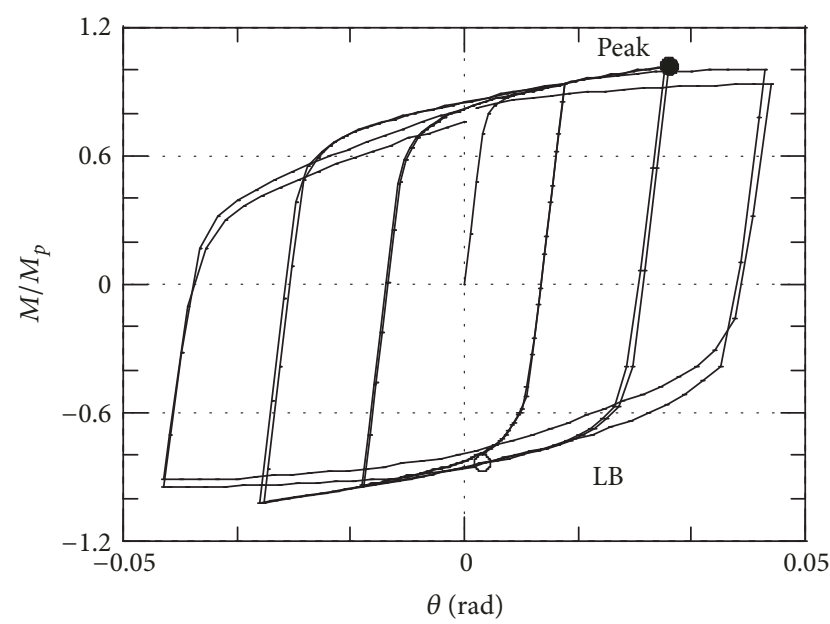

(b)

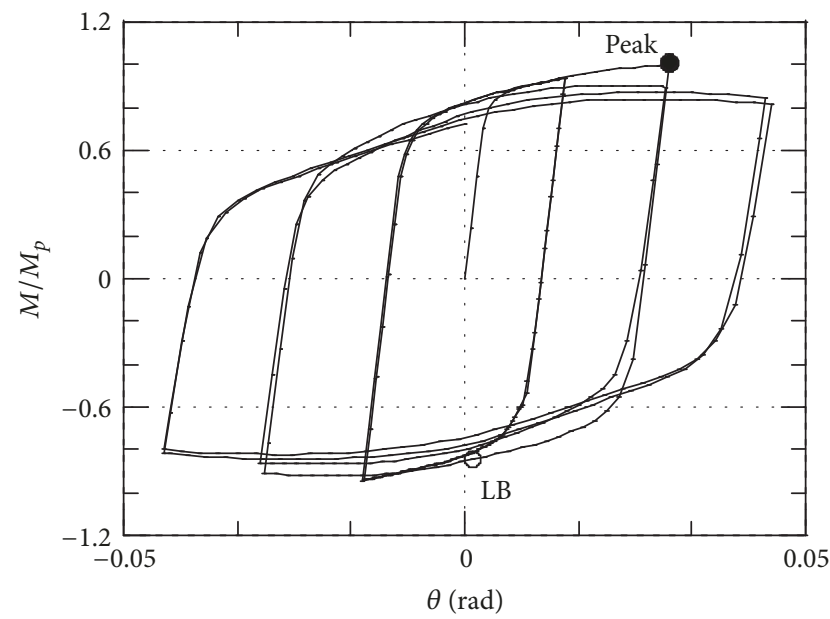

(d)

Figure 2: The hysteresis loop of beam-end moment in W36 × 194 RBS beams: (a) Standard RBS; (b) RBS-SLB; (c) VSTF ([3]); (d) HSTF.

vertical stiffeners (called "VSTF"), and (d) is the beam with horizontal stiffeners (called "HSTF"). The beam-end moment is normalized by the full plastic moment $\left(M_{p}\right)$. The strength reduces subsequently after the occurrence of local buckling in all models. In these figures, an open circle $(O)$ indicates the local buckling point, and filled circle $(\bullet)$ indicates the peak point. The strength deterioration is observed in all analysis models. The local buckling point was determined by visually checking the deformed shape of FEM.

Figure 3 shows the relationship between the last strength $\left(M_{\text {last }}\right)$ of each loading cycle. Figure $3(\mathrm{a})$ is $W 24 \times 76$, (b) is $W 30 \times 99$, and $(c)$ is $W 36 \times 194$. It shows that almost all models with SLB or stiffeners have the last strength more than $0.8 M_{p}$. For Standard RBS, the last strength $\left(M_{\text {last }}\right)$ is less than $0.8 M_{p}$. Comparing the last strength of first cycle $(0.015 \mathrm{rad})$ with the last strength of sixth cycle $(0.045 \mathrm{rad})$, it is indicated that for the $W 24 \times 76$ and $W 36 \times 194$ of Standard RBS beam, the last strength of the sixth cycle is about $20 \%$ less than the last strength of first cycle. For the $W 30 \times$ 99 beam, the strength reduced significantly by $67 \%$ of the last strength of first cycle. For the RBS-SLB beam, it shows that the last strength $(0.045 \mathrm{rad})$ exceeds $0.8 M_{p}$. For $W 30 \times$ 99 , the strength reduced by $26 \%$ of the maximum strength eventually.

SLB is effective in lateral buckling, and the strength degradation of beam is due to local buckling. The strength of HSTF (the beam with horizontal stiffeners) and VSTF (the beam with vertical stiffeners) is higher than Standard RBS. The stiffeners are effective for local buckling. The occurrence of local buckling is delayed by stiffeners, but the stiffeners cannot completely restraint local buckling.

\section{Behavior of RBS Beam with Vertical Stiffeners and Horizontal Stiffeners}

3.1. Length of Vertical Stiffeners. In order to prevent the strength degradation caused by local buckling, vertical and horizontal stiffeners were positioned as in Figure 4. To restrain stress concentration at flange, vertical stiffeners are shorter than beam depth. The stiffeners do not touch with flange. Because only vertical short stiffeners cannot sustain strength, arrangement of short vertical stiffeners and 


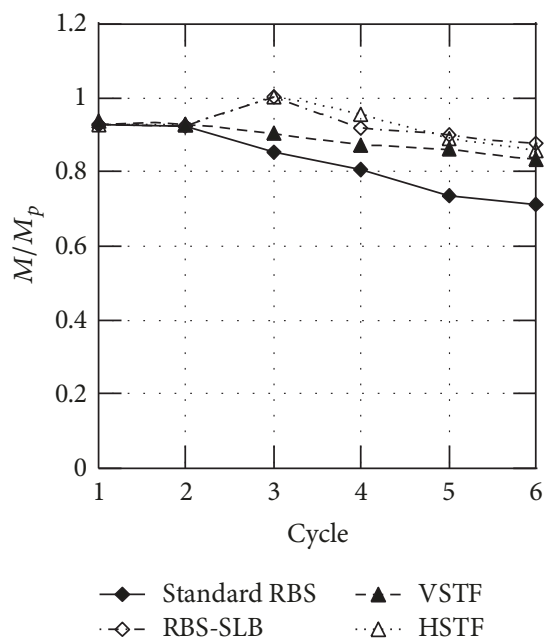

(a)

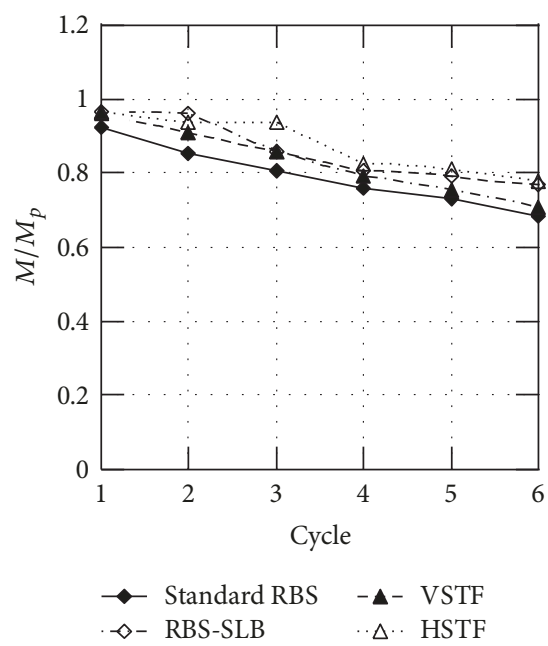

(b)

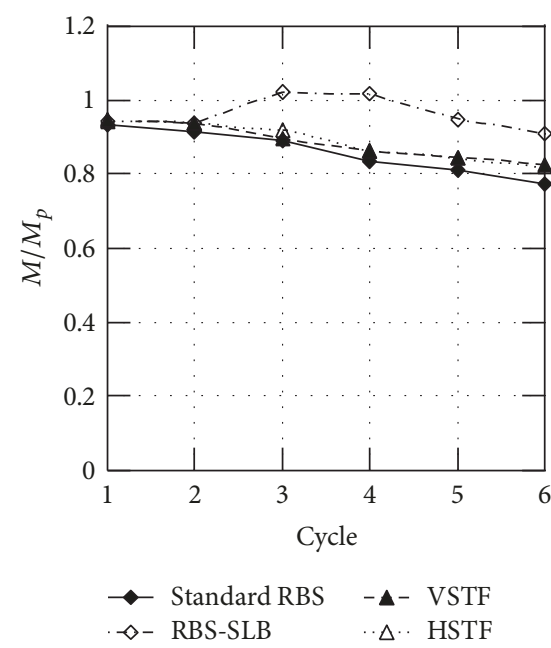

(c)

FIGURE 3: The last strength of each cycle: (a) W24 × 76; (b) W30 × 99; and (c) W36 × 194 .

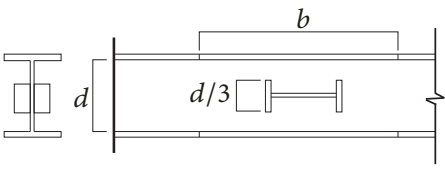

(a)

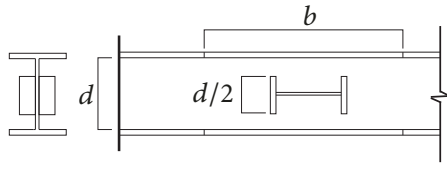

(b)

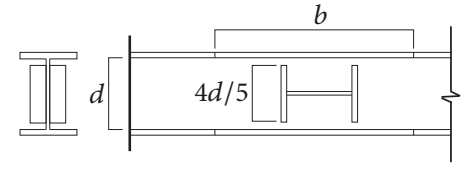

(c)

FIGURE 4: The arrangement of vertical and horizontal stiffeners in RBS beam ([5]): (a) VHSTF-1/3; (b) VHSTF-1/2; and (c) VHSTF-4/5.
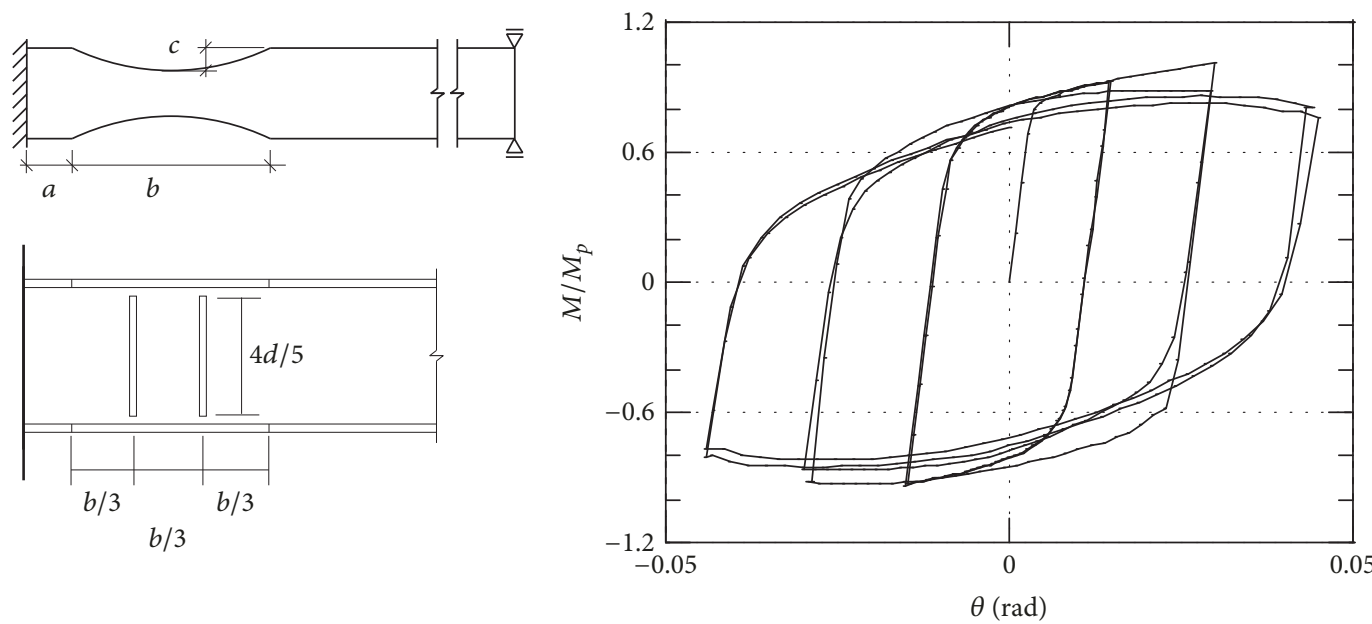

FIGURE 5: The hysteresis loop of beam-end moment in $W 24 \times 76$ RBS beams with vertical short stiffeners.

horizontal stiffeners is proposed. Figure 5 shows the analysis result of RBS beam with vertical stiffeners shorter than beam depth $(W 24 \times 76)$. The strength deteriorates gradually, and last strength is lower than $0.8 M_{p}$.

Figure 6 shows the relationship between the beam-end moment $\left(M / M_{p}\right)$ and the beam-end rotation $(\theta)$ of beams with vertical and horizontal stiffeners for $W 36 \times 194$. The beam-end rotation is calculated by the vertical displacement of loading point divided by beam length $(L / 2)$. Parameter is length of vertical stiffeners. The length of vertical stiffener is $d / 2$ (called "VHSTF-1/2"), $d / 3$ (called "VHSTF-1/3"), and $4 d / 5$ (called "VHSTF-4/5"). However last strength of Standard RBS is $0.75 M_{p}$; last strength of VHSTF-4/5 is over $0.8 M_{p}$. Vertical and horizontal stiffeners are effective for local buckling.

Figure 7 shows the relationship between the last strength and cycle. The vertical axis is the beam-end moment $\left(M / M_{p}\right)$, and the horizontal axis is cycle. From Figure 7 VHSTF-4/5 sustains $0.8 M_{p}$, but last strengths of VHSTF-1/2 and VHSTF$1 / 3$ are less than $0.8 M_{p}$ at sixth cycle. Evidently, the strength deterioration becomes smaller with the increase of the length of vertical stiffener. VHSTF-4/5 is most effective. 


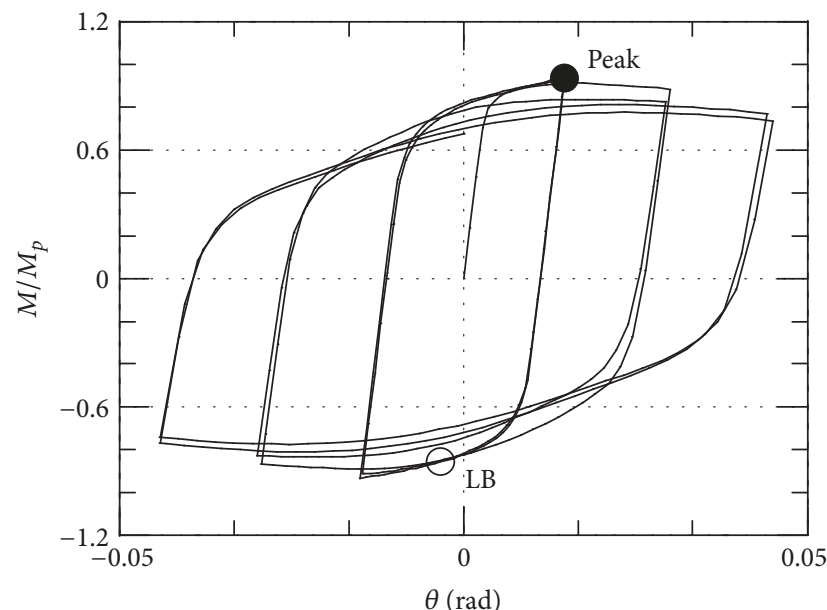

(a)

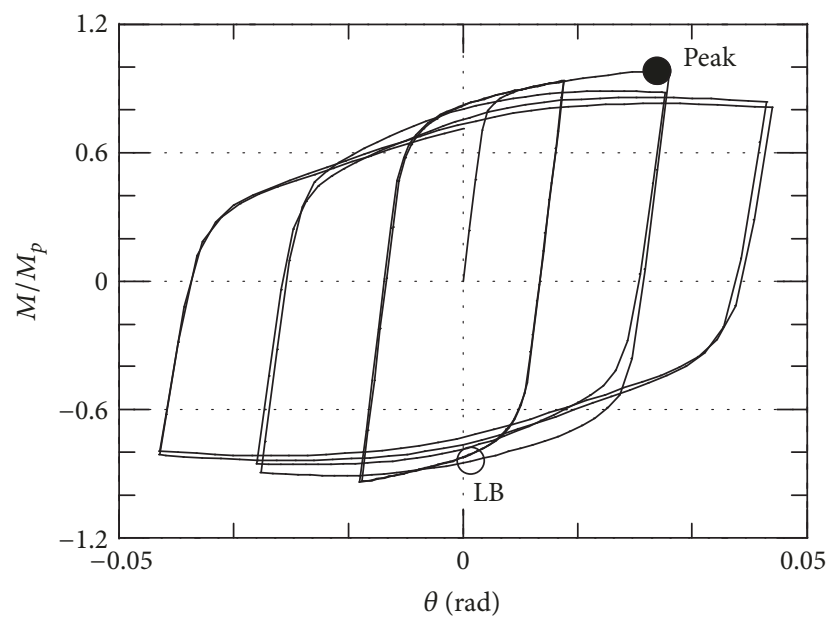

(c)

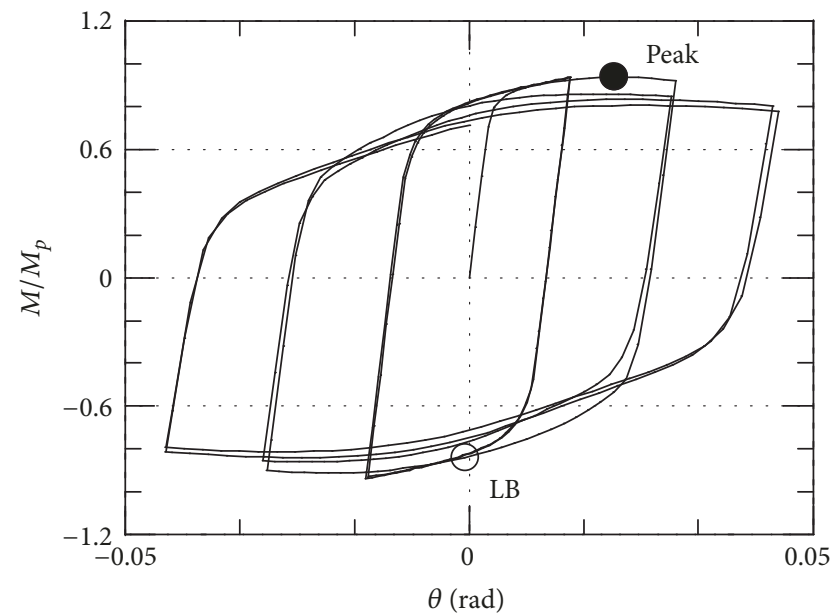

(b)

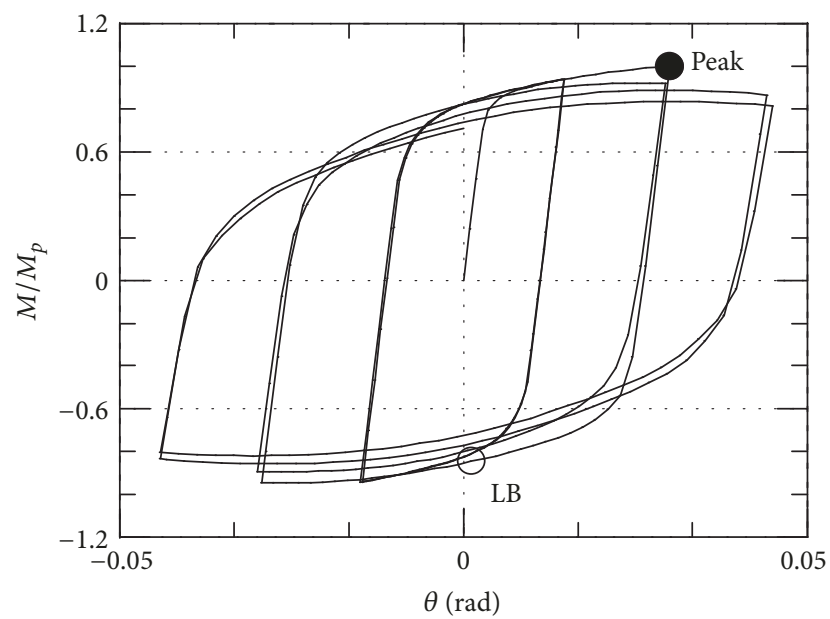

(d)

FIGURE 6: The hysteresis loop of beam-end moment in W36 × 194 RBS beams: (a) Standard RBS; (b) VHSTF-1/3; (c) VHSTF-1/2; (d) VHSTF$4 / 5$.

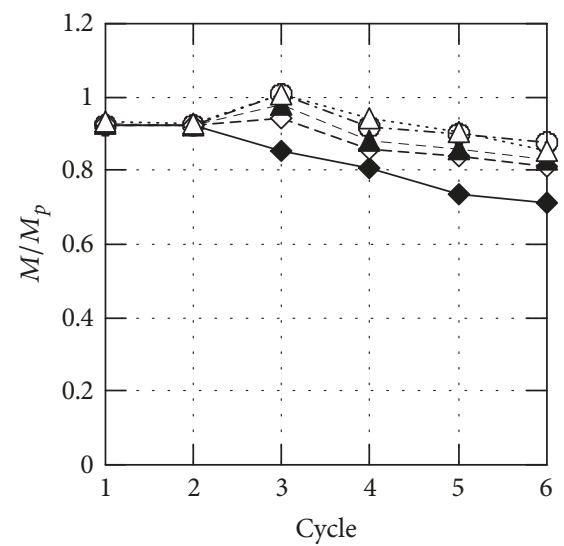

- Standard RBS

$\Theta-$ RBS-SLB $-\diamond$ VHSTF-1/3

(a)
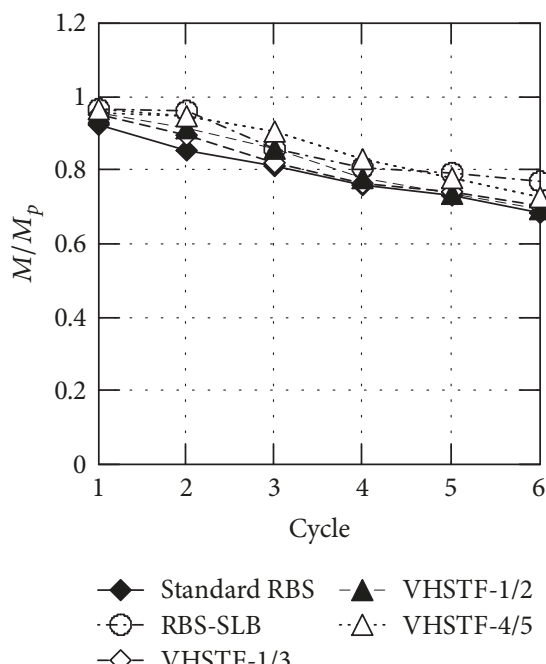

(b)
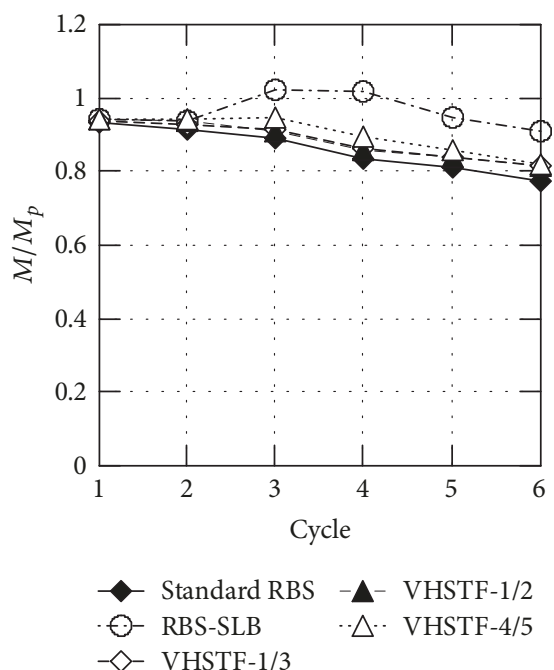

(c)

Figure 7: The last strength of each cycle: (a) W24 × 76; (b) W30 × 99; and (c) W36 × 194 ([5]). 

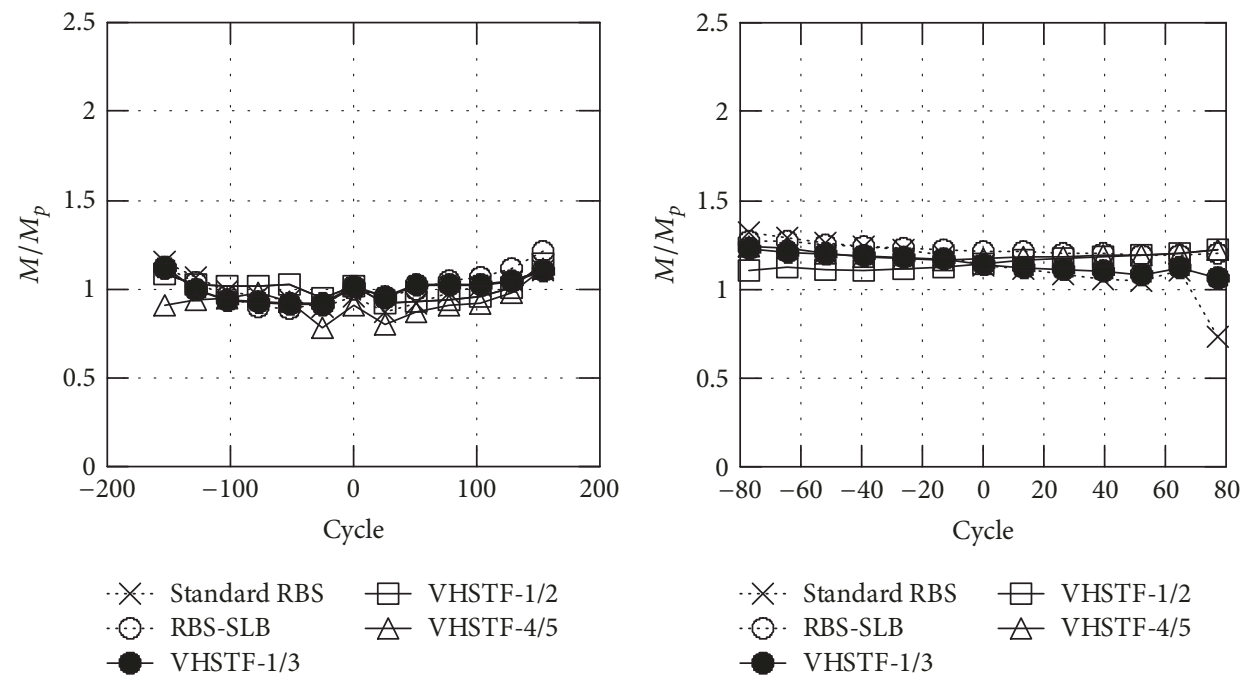

(a)

(b)

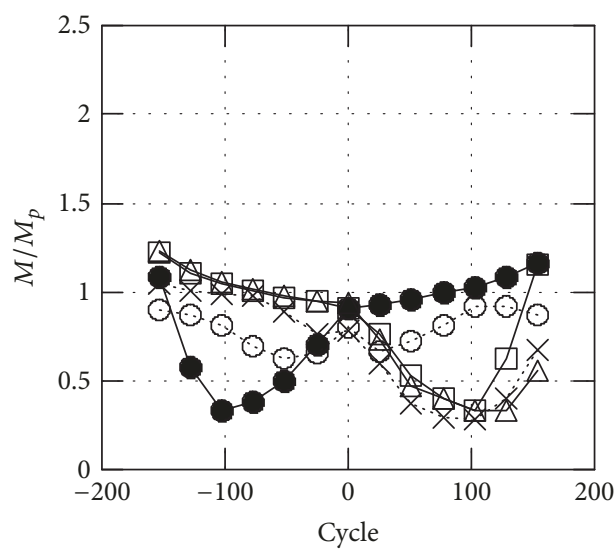

$\begin{array}{ll}\text { - Standard RBS } & \square \text { VHSTF-1/2 } \\ - \text { RBS-SLB } & \triangle \text { VHSTF-4/5 } \\ - \text { VHSTF-1/3 } & \end{array}$

(c)
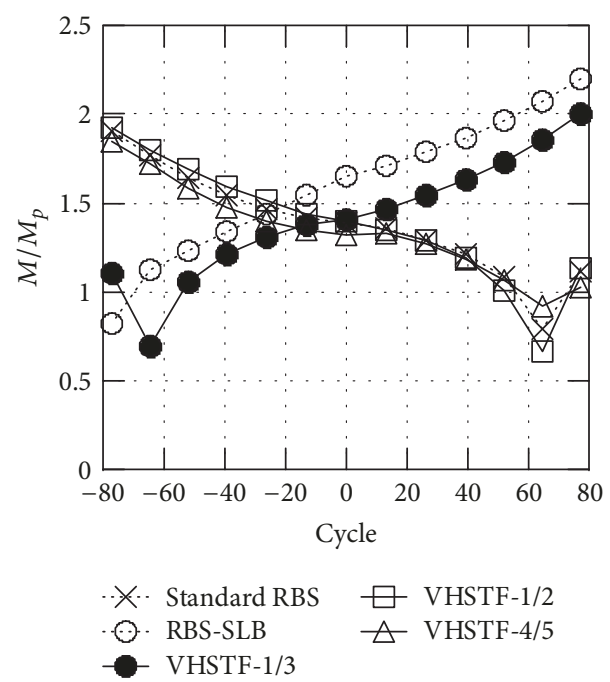

(d)

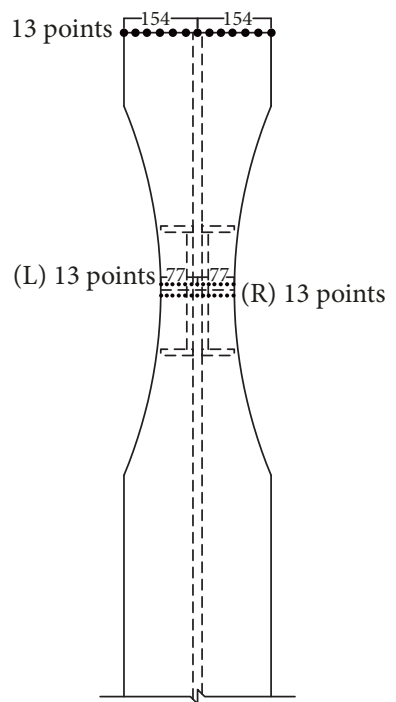

(e)

FIGURE 8: The stress distribution at the lower and upper flange of the fixed-end and RBS portion (W36 $\times 194)$ : (a) upper flange at fix end; (b) lower flange at fix end; (c) upper flange at RBS portion; (d) lower flange at RBS portion; (e) the stress monitoring points.

3.2. Stress Distribution. From the preceding analysis, it is confirmed that sixth last strength of RBS beam locating $\mathrm{H}$ shaped form of vertical and horizontal stiffeners in $1 / 3$ length of RBS $(b / 3)$ can maintain almost the same strength with the RBS-SLB beams or above $0.8 M_{p}$. However, stress concentration may occur around the stiffener. In addition, because the RBS section was reinforced by horizontal stiffeners, the stress around beam-to-column Joint may increase. Therefore, it is necessary to examine the stress state at the fixed beamend and central part of RBS portion. Here VHSTF-1/3, VHSTF-1/2, and VHSTF-4/5 are discussed and compared with Standard RBS beams and RBS-SLB.

Figure 8 shows the Von Mises stress distribution at the fixed-end and the RBS central portion of the 6th cycle for W36 $\times 194$ beams. Figures $8(\mathrm{a})$ and $8(\mathrm{~b})$ show the stress distribution of upper flange and lower flange on the fixedend section, and (c) and (d) show the result of RBS portion. The vertical axis is the stress normalized by the yield stress, and the horizontal axis is the position of monitoring nodes, shown in Figure 8(e).

Figure 8 shows that the stress at the fixed-end tends to increase, and the stress at the RBS portion tends to decrease by placing stiffener. As shortening the length of the vertical stiffener, the stress around the beam-end reduced, and the stress at RBS portion increased. Similar maximum stress to RBS-SLB is observed at VHSTF-4/5.

Table 2 is the maximum stress at the fixed-end and RBS portion for three sections at the maximum amplitude of sixth cycle. For $W 24 \times 76$, the stress increase at the beam-end is greater than that of RBS-SLB. At the RBS portion, maximum stress ratio of VHSTF-4/5 is 1.80 . For $W 30 \times 99$ and $W 36 \times$ 194 , the stress at the fixed-end increases to $1.51 \sigma_{y}$ and $1.85 \sigma_{y}$ in VHSTF-4/5, but the stress is smaller than that of RBS-SLB.

Although the maximum stress of VSTF is twice yield stress (the study of Li et al. [3]), the influence of vertical and horizontal stiffeners on the flange of RBS portion is smaller 
TABLE 2: The maximum stress at the maximum displacement of the RBS beams during the sixth cycle.

\begin{tabular}{|c|c|c|c|c|c|c|c|c|}
\hline & & RBS & SLB & VSTF & HSTF & VHSTF-1/3 & VHSTF-1/2 & VHSTF- $4 / 5$ \\
\hline \multirow{2}{*}{$W 24 \times 76$} & Fixed end & 1.10 & 1.12 & 1.20 & 1.13 & 1.13 & 1.20 & 1.19 \\
\hline & RBS section & 1.63 & 1.56 & 2.06 & 1.65 & 1.77 & 1.77 & 1.80 \\
\hline \multirow{2}{*}{$W 30 \times 99$} & Fixed end & 1.15 & 1.21 & 1.12 & 1.26 & 1.21 & 1.22 & 1.18 \\
\hline & RBS section & 1.43 & 1.76 & 1.83 & 1.51 & 1.55 & 1.50 & 1.51 \\
\hline \multirow{2}{*}{$W 36 \times 194$} & Fixed end & 1.15 & 1.21 & 1.35 & 1.23 & 1.16 & 1.22 & 1.23 \\
\hline & RBS section & 1.90 & 2.20 & 2.07 & 1.90 & 2.00 & 1.93 & 1.85 \\
\hline
\end{tabular}

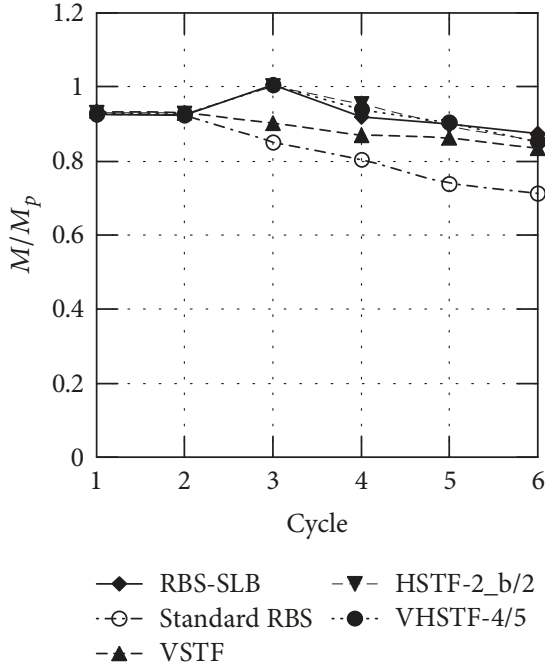

(a)

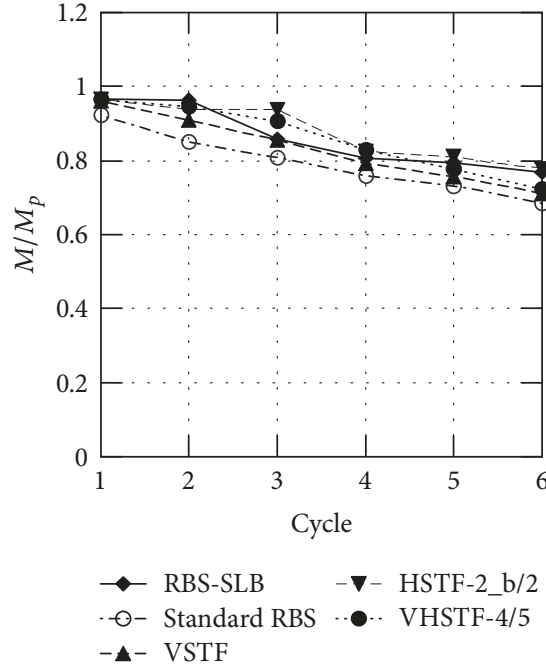

(b)

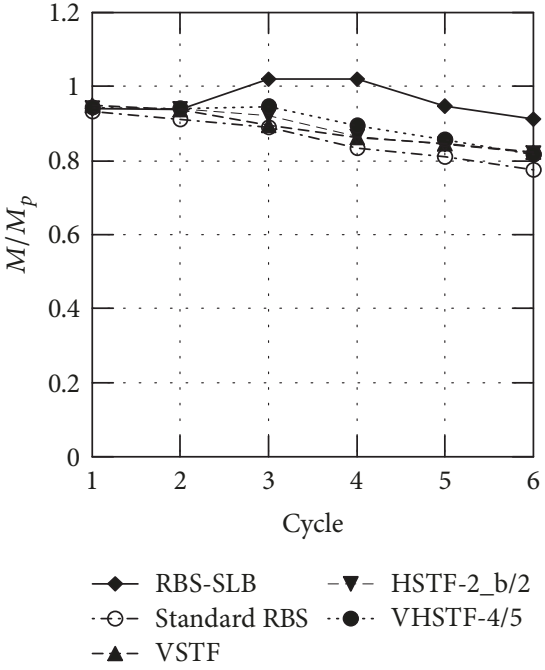

(c)

FIGURE 9: Comparison of the last strength of each cycle ([5]): (a) $W 24 \times 76$; (b) $W 30 \times 99$; and (c) W36 194.

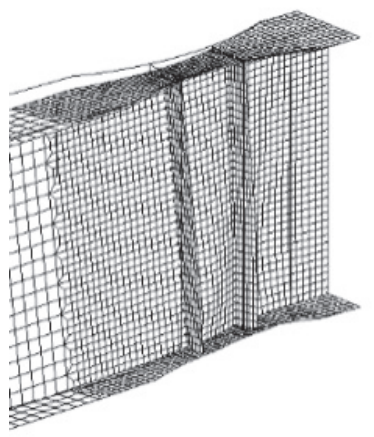

(a)

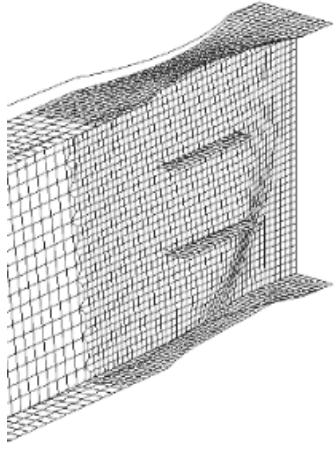

(b)

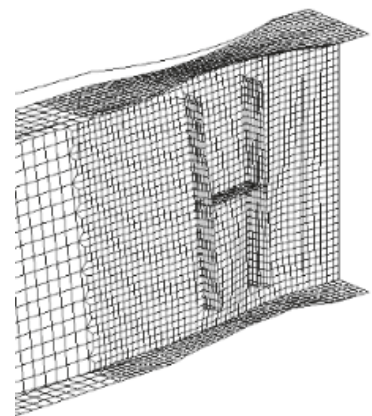

(c)

FIgURE 10: A comparison of deformation in RBS portion at the sixth cycle $(W 36 \times 194)$ ([5]): (a) VSTF; (b) HSTF; (c) VHSTF-4/5.

than VSTF. Moreover the maximum stress of HSTF is similar to that of VHSTF.

From the above results, the method to satisfy strength and performance capacity is using 2 pairs of $\mathrm{H}$ shaped stiffeners of length of $4 d / 5$.

\section{Comparison between VSTF, HSTF, and VHSTF-4/5}

Figure 9 shows the relationship between the last strength $\left(M / M_{p}\right)$ and cycle. Figure $9(\mathrm{a})$ is $W 24 \times 76$, (b) is $W 30 \times 99$, and (c) is $W 36 \times 194$. HSTF and VHST are almost the same.
The strengths of $W 24 \times 75$ and $W 30 \times 99$ are similar to RBSSLB. VHSTF-4/5 is more effective than VHST. Because of the local buckling of flange, the strength of VSTF decreases. For $W 36 \times 194$, the strength of VHSTF-4/5 is lower than that of RBS-SLB, but strength requirement is satisfied.

Figure 10 shows deformation of VSTF, HSTF, and VHSTF-4/5 at the sixth cycle. The deformation at flange of VHSTF-4/5 is smaller than that of VSTF. The deformation at RBS portion of VHSTF-4/5 is smaller than that of HSTF.

From the above results, the strength of VHSTF-4/5 is similar to that of VSTF and HSTF, but deformation of VHSTF-4/5 is smaller than that of VSTF and HSTF. 


\section{Conclusions}

This paper presents a numerical study of local instability and the effect of vertical and horizontal stiffeners on RBS beams subjected to cyclic loading. The major findings obtained from this study are summarized as follows:

(1) Arranging $\mathrm{H}$ shaped vertical and horizontal stiffeners at RBS portion is effective in preventing local instability as vertical stiffeners (VSTF, Li et al. [3]) and horizontal stiffeners (HSTF, Yu et al. [4]). The effective length of vertical stiffener is $80 \%$ beam depth (VHSTF-4/5).

(2) Though the strengths of VSTF, HSTF, and VHSTF$4 / 5$ are almost the same, deformation of VHSTF- $4 / 5$ is smallest among the 3 types.

(3) The stress at flange of VHSTF-4/5 is not so large; the maximum stress of RBS-SLB and VHSTF- $4 / 5$ is almost same.

\section{Conflicts of Interest}

The authors declare that there are no conflicts of interest regarding the publication of this paper.

\section{References}

[1] M. D. Engelhardt and T. A. Sabol, "Seismic-resistant steel moment connections: developments since the 1994 Northridge earthquake," Progress in Structural Engineering and Materials, vol. 1 , no. 1, pp. 68-77, 1997.

[2] C.-M. Uang and C.-C. Fan, "Cyclic stability criteria for steel moment connections with reduced beam section," Journal of Structural Engineering, vol. 127, no. 9, pp. 1021-1027, 2001.

[3] F.-X. Li, I. Kanao, J. Li, and K. Morisako, "Local buckling of RBS beams subjected to cyclic loading," Journal of Structural Engineering, vol. 135, no. 12, pp. 1491-1498, 2009.

[4] Z. Yu, Y. Wada, I. Kanao, and K. Morisako, "Local Buckling Behavior of RBS Beams with Horizontal Stiffeners Subjected to Cyclic Loading," Journal of Structural Engineering, Architectural Institute of Japan, vol. 63B, pp. 525-531, 2017.

[5] T. He, Y. Wada, I. Kanao, Z. Yu, and K. Morisako, Study on Stiffeners Layout for RBS Beam, Architectural Institute of Japan Kinki Chapter Architectural Research Meeting, Architectural Institute of Japan Kinki Branch, 2016.

[6] American Institute of Steel Construction (AISC), Seismic Provisions for Structure Steel Buildings, ANSI/AISC 341-10, Chicago, Ill, USA.

[7] American Institute of Steel Construction (AISC), Prequalified Connections for Special and Intermediate Steel Moment Frames for Seismic Applications, ANSI/AISC 358-10, Chicago, Ill, USA, 2010.

[8] M. D. Engelhardt, "Design of reduced beam section moment connections," in Proceedings of the Processing North American Steel Construction Conference, American Inst. of Steel Construction, Chicago, Ill, USA, 1999. 


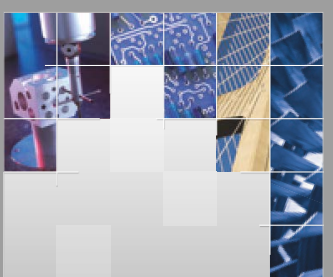

\section{Enfincering}
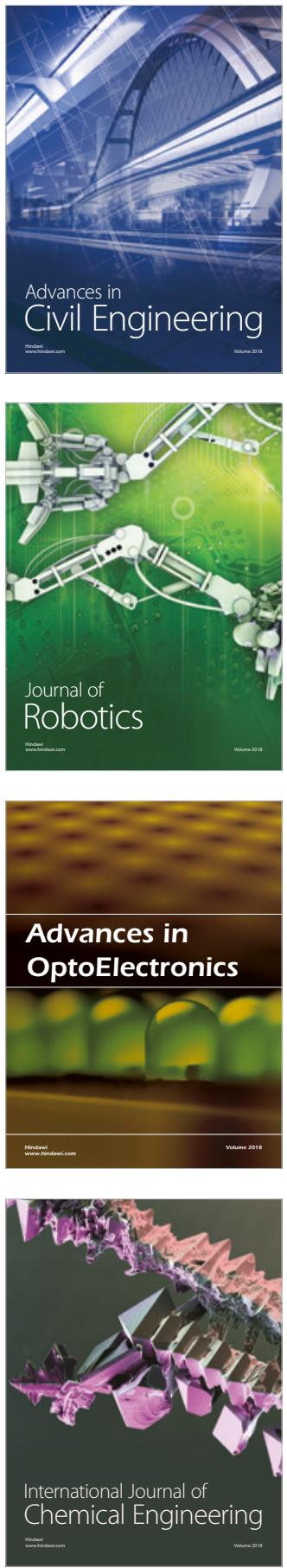

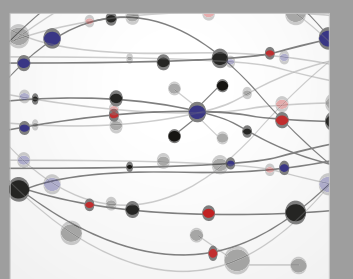

\section{Rotating \\ Machinery}

The Scientific World Journal

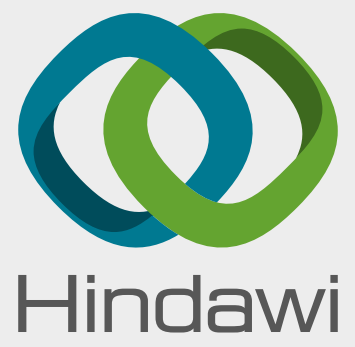

Submit your manuscripts at

www.hindawi.com
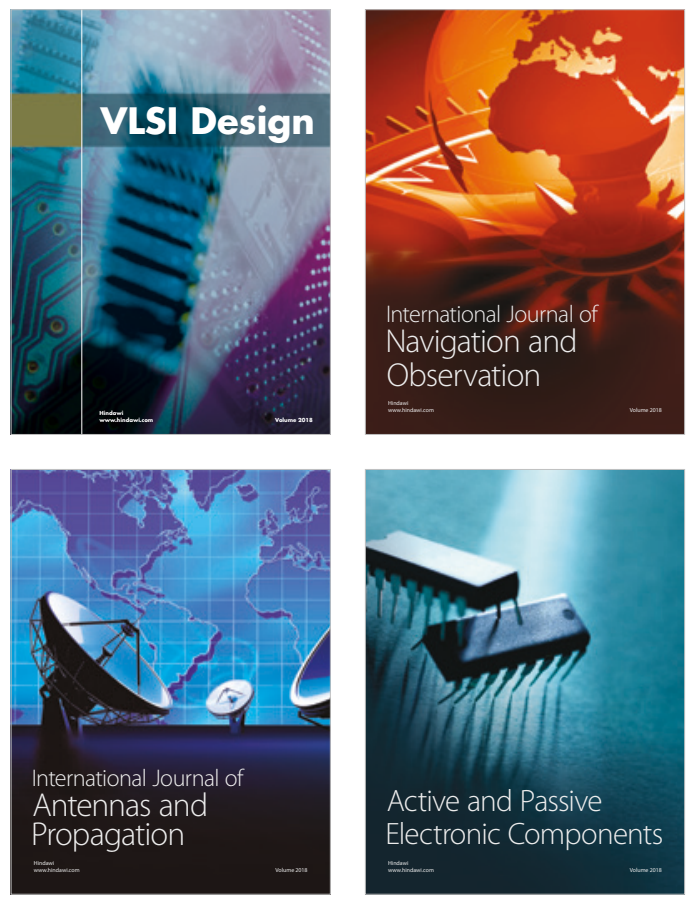
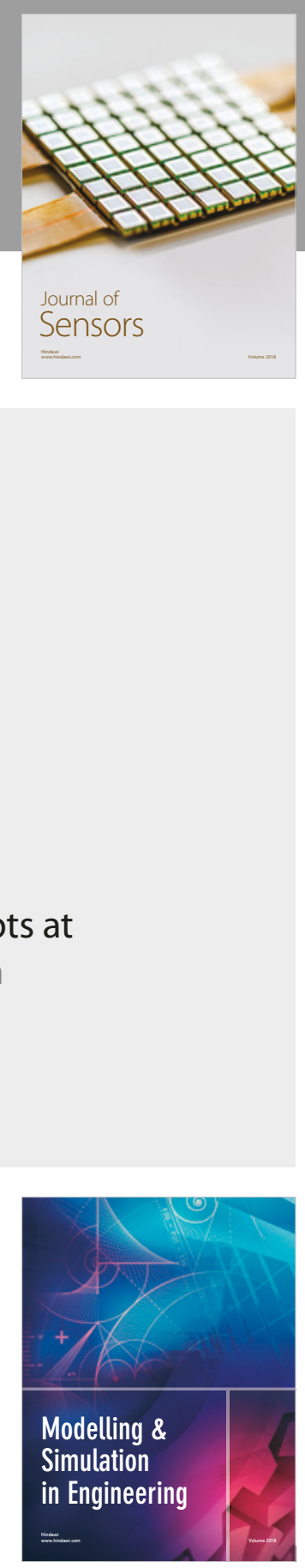

\section{Advances \\ Multimedia}
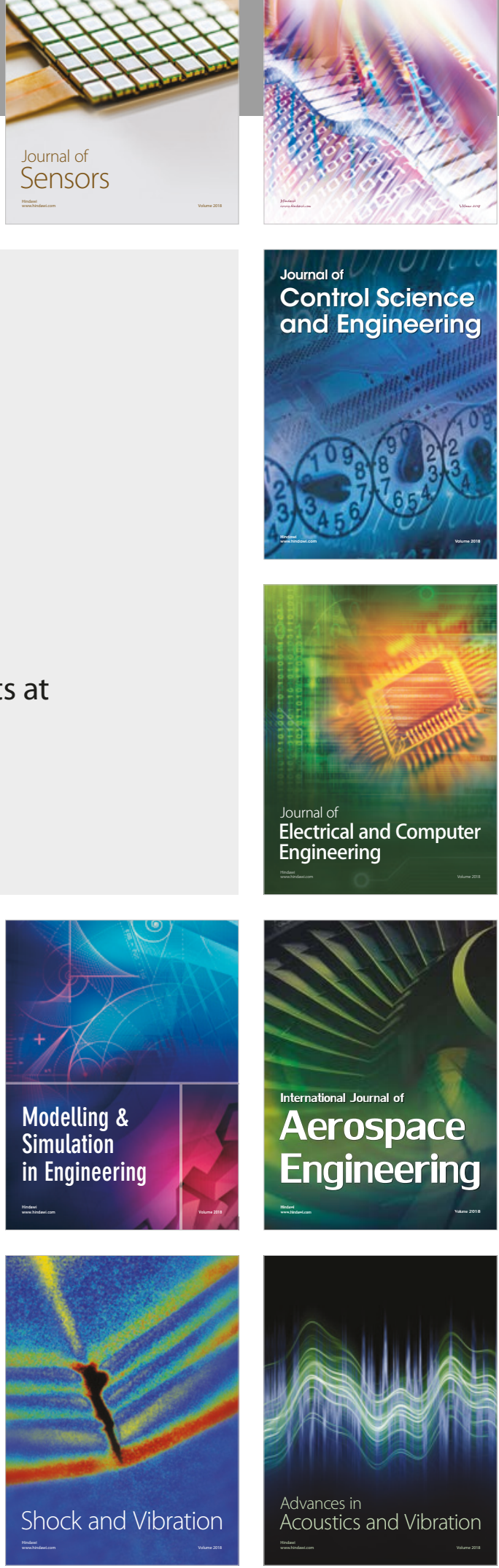